\title{
Ultra-Low-Temperature Cofired Ceramic Substrates with Low Residual Carbon for Next-Generation Microwave Applications
}

\author{
Nina Joseph, ${ }^{* \bullet}$ Jobin Varghese, ${ }^{\circledR}$ Merja Teirikangas, Timo Vahera, and Heli Jantunen \\ Microelectronics Research Unit, Faculty of Information Technology and Electrical Engineering, University of Oulu, FI-90014 Oulu, \\ Finland
}

\section{Supporting Information}

ABSTRACT: High-temperature cofired ceramics and low-temperature cofired ceramics are important technologies in the fabrication of multilayer ceramic substrates for discrete devices, electronics packages, and telecommunications. However, there is a place and need for materials with lower fabrication temperatures to decrease the associated energy consumption. The present paper studies the feasibility of two ultra-low sintering temperature cofired ceramic materials, copper molybdate and copper molybdate- $-\mathrm{Ag}_{2} \mathrm{O}$, sinterable at 650 and $500{ }^{\circ} \mathrm{C}$, respectively, for multilayer substrates using tape casting. The slurry composition developed uses environmentally friendly organics and a nontoxic binder and solvent. Additionally, the green cast tapes exhibit very low residual carbon (less than 5\%) after sintering on analysis by X-ray photoelectron spectroscopy. The multilayer substrates show a permittivity value of about 8 with a low dielectric loss in the range of $10^{-5}$ to $10^{-4}$ in the frequency range of $2-10 \mathrm{GHz}$ along with a low coefficient of thermal expansion in the range of $4-5 \mathrm{ppm} /{ }^{\circ} \mathrm{C}$ and good compatibility with an $\mathrm{Al}$ electrode. Thus, these proposed substrates have much promise, with good thermal, mechanical, and dielectric properties comparable to commercial substrates while also providing an energy and environment-friendly solution.

KEYWORDS: $\mathrm{CuMoO}$, ULTCC, environmental friendly, tape casting, microwave substrates

\section{INTRODUCTION}

The ultra-low temperature cofired ceramic (ULTCC) technology has attracted interest recently because of its efficient energy-saving characteristics as compared to the conventional high-temperature cofired ceramic (HTCC) and low-temperature cofired ceramic (LTCC) technologies. ${ }^{1}$ The LTCC technology has been the standard technology for the integration of components and substrates for high-frequency applications for several decades. The LTCC technology enables the tape casting of dielectric materials for multilayer structures cofired with metal electrodes at a low temperature $\left(\sim 850{ }^{\circ} \mathrm{C}\right)$. For microwave applications, the used dielectric materials must have a low dielectric constant to increase the signal speed and a low dielectric loss to improve the frequency selectivity and the substrates are expected to meet the requirements imposed by growths in the technology. Compared to the printed circuit board materials, the ceramics can provide better thermal stability with a low thermal expansion coefficient and high thermal conductivity as well as a high integration potential to deliver good performance at high frequencies. $^{2,3}$ In the case of the ULTCC technology, the sintering temperature is commonly much less than $700{ }^{\circ} \mathrm{C}$, thus enabling lower energy consumption and easier integration of different materials into the same multilayer structure ${ }^{4}$ while at the same time being feasible for the same application areas as the LTCC technology. ${ }^{1}$ This technology provides an alternate path to solve the problem of energy crisis by conserving the existing energy used in the present technology rather than looking for a new source of energy and is a simple, easy, and cheap method.

In the last five years, several ULTCC compositions have been reported, ${ }^{1,4-8}$ but only a few of them have been explored for multilayer substrates through tape casting with a low burnout temperature, ${ }^{9-13}$ and our work is an attempt to examine this aspect. In this work, the focus is on the investigation of the environmentally friendly processing aspects of tape casting formulations, which are based on the nontoxic chemical solvent dimethyl carbonate (DMC) $)^{14,15}$ together with a biodegradable and biocompatible binder poly(propylene carbonate) (PPC). ${ }^{10}$ This binder system has been successfully used for tape casting of ULTCC compositions ${ }^{10,12,13}$ which have a lower burnout temperature. However, no studies on the carbon content of the cast tape before and after sintering have been reported. The carbon analysis gives information about the carbon emission during the processing as well as the residual carbon of the substrate. This is an important aspect of this

Received: April 25, 2019

Accepted: June 11, 2019

Published: June 11, 2019 
work because residual carbon can degrade the dielectric properties of the final product.

In our previous research, it was observed that the $\mathrm{CuMoO}_{4}$ (CMO) ceramic exhibits good thermal and dielectric properties with an excellent densification of $96 \%$ by sintering at 650 ${ }^{\circ} \mathrm{C}$, and its composite obtained by adding $0.5 \mathrm{wt} \%$ of $\mathrm{Ag}_{2} \mathrm{O}$ was also a good candidate for substrate applications with a much lower sintering temperature of $500{ }^{\circ} \mathrm{C}$. These studied ceramics also exhibited good chemical compatibility with aluminum, which can be used for embedded electrodes. ${ }^{16,17}$ Hence, our present work is an attempt to transform these ULTCC materials into ULTCC substrates by tape casting using an environmentally benign slurry composition and postprocessing techniques such as multilayer lamination, screen-printing, and cofiring, together with an investigation of their microstructural, dielectric, and thermal characteristics.

\section{MATERIALS AND METHODS}

Preparation of $\mathrm{CMO}$ Ceramic and $\mathrm{CMO}-\mathrm{Ag}_{2} \mathrm{O}$ Ceramic Composites. The CMO ceramic was prepared using the solid-state ceramic route by mixing stoichiometric amounts of high-purity $\mathrm{CuO}$ ( $>99 \%$, Alfa Aesar) and $\mathrm{MoO}_{3}(>99 \%$, Alfa Aesar) in an ethanol medium for $12 \mathrm{~h}$, with subsequent drying, followed by calcination at $550{ }^{\circ} \mathrm{C}$. The $\mathrm{CMO}-\mathrm{Ag}_{2} \mathrm{O}(\mathrm{CMOA})$ ceramic composite was prepared by mixing 0.5 wt $\%$ of $\mathrm{Ag}_{2} \mathrm{O}$ (99+ \%, Alfa Aesar) into the CMO powder in the ethanol medium for $12 \mathrm{~h}$, followed by drying.

Preparation of CMO and CMOA Substrates by Tape Casting. To prepare the tape casting slurry, DMC (Sigma-Aldrich, St. Louis, MO) was used as a solvent with PPC (QPAC40, Empower Materials, New Castle, DE) as the binder and butyl benzyl phthalate (S160, Richard E. Mistler, Yardley, Pennsylvania) and polyethylene glycol (UCON 50HB2000, Richard E. Mistler) as the type I and type II plasticizers, respectively. Initially, the ceramic powder (CMO/ CMOA) was mixed with DMC and PPC for $12 \mathrm{~h}$ by ball milling. The milling was continued for $24 \mathrm{~h}$ after the addition of the two plasticizers. The resultant slurry was cast on a silicone-coated Mylar carrier tape at a speed of $0.8 \mathrm{~m} / \mathrm{min}$ using a laboratory caster (Unicaster 2000, Leeds, UK) and a $400 \mu \mathrm{m}$ doctor blade. The dried green cast tape was peeled off for further processing. Aluminum ink (AL-PS1000, Applied Nanotech, Inc., USA) cofirable in the temperature range of $500-650{ }^{\circ} \mathrm{C}$ was screen-printed, followed by drying at room temperature for cofiring analysis, which is performed in the normal air atmosphere. For further characterization, five green cast tapes were stacked by vacuum lamination and isostatic pressing at $75^{\circ} \mathrm{C}, 20 \mathrm{MPa}$ for $10 \mathrm{~min}$ (Turbovac $430 \mathrm{STE}$ vacuum machine and PTC IL-4008, Isostatic laminator). The stacked tapes were sintered at their respective sintering temperatures $\left(\mathrm{CMO}-650{ }^{\circ} \mathrm{C} / 2 \mathrm{~h}\right.$; CMOA$500{ }^{\circ} \mathrm{C} / 2 \mathrm{~h}$ ) with an optimized sintering profile. The process flow chart is shown in Figure 1.

Two commercial LTCC tapes 9k7 (single green layer thickness $0.249 \mathrm{~mm}$ ) and 951 (single green layer thickness $0.251 \mathrm{~mm}$ ) (Dupont, US) were used to compare the X-ray photoelectron spectroscopy (XPS) measurement results. The four-layer stacks were sintered at $850{ }^{\circ} \mathrm{C}$ and had thicknesses of 0.822 and $0.864 \mathrm{~mm}$, respectively.

Characterization. The particle size and specific surface area of the ceramic powders were analyzed using the laser diffraction method (Beckman Coulter LS13320) and a particle surface area analyzer (G.W. Berg \& Co. Micrometrics ASAP 2020), respectively. The tensile strength of the green cast tapes was measured by a tensile strength measurement setup (TST 350, Linkam Scientific Instruments Ltd., Survey, UK) and Linksys 32 software at room temperature with a speed of $100 \mu \mathrm{m} / \mathrm{s}$ using standard dumbbell-shaped samples (length $36.2 \mathrm{~mm}$ and width $3.1 \mathrm{~mm}$ ). The burnout of the organic additives was studied using differential scanning calorimetric (DSC) measurement/thermogravimetric (TG) analysis (Netzsch 404 F3, Selb). The bulk density of the sintered samples was measured in an ethanol medium using the Archimedes method. The shrinkage was calculated

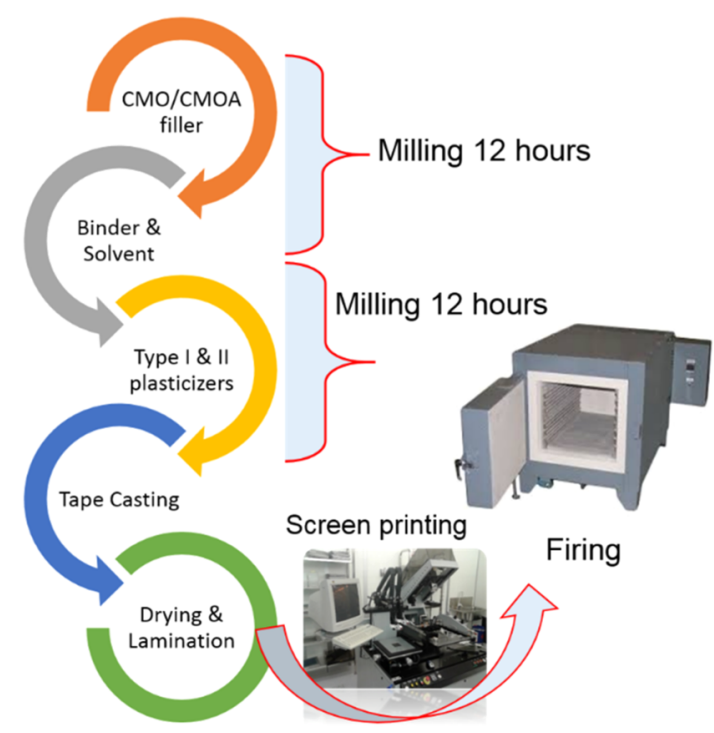

Figure 1. Tape casting and postprocessing flow chart.

from the dimensions of the laminated and sintered substrates. For XPS analysis, a Fisher Scientific, ESCALAB $250 \mathrm{Xi}$ using the $\mathrm{Mg} \mathrm{K} \alpha$ $\mathrm{X}$-ray source was used, and the spectrometer was calibrated with reference energies of $\mathrm{Au} 4 \mathrm{f}_{5 / 2}(83.9 \pm 0.1 \mathrm{eV})$ and $\mathrm{Cu} 2 \mathrm{p}_{3 / 2}(932.7 \pm$ $0.1 \mathrm{eV}$ ). An angle of $90^{\circ}$ was maintained between the surface and the analyzer (take-off angle) for the measurement. The $\mathrm{C} 1 \mathrm{~s}$ peak with a binding energy at $284.8 \mathrm{eV}$ corresponding to the surface contamination was used for binding energy calibration for the sample charging correction. ${ }^{18,19}$ The surface roughness of the green and sintered substrates was measured using an atomic force microscope (Veeco dimension 3100130 SPM) operating in the contact mode regime, and their microstructure was analyzed using field emission scanning electron microscopy (SEM, Zeiss Ultra Plus, Germany). Microwave dielectric properties of the green and sintered substrates were measured by the split-post dielectric resonator (SPDR) (QWED, Poland) technique using a vector network analyzer (10 MHz to $20 \mathrm{GHz}$, Rhode \& Schwarz, ZVB20, Germany) and their temperature dependence by using a furnace (Espec SU-261) operating at -40 to $80{ }^{\circ} \mathrm{C}$ integrated with the microwave measurement setup. With this method, the total uncertainty of the determination of the relative permittivity was about $0.5 \%$ and the dielectric loss was in the range of $10^{-5} \cdot{ }^{20,21}$ Cylindrical samples of diameter $8 \mathrm{~mm}$ and thickness $15 \mathrm{~mm}$ were used to measure the linear coefficient of thermal expansion (CTE) using a dilatometer (NETZSCH DIL 402 PC/4, Germany).

\section{RESULTS AND DISCUSSION}

Tape Casting and Lamination. The CMO and CMOA powders had an average particle size in the range of 2.3-2.5 $\mu \mathrm{m}$ with a surface area of $\sim 3.5 \mathrm{~m}^{2} / \mathrm{g}$. These ceramic powder properties are in the range considered desirable to obtain an optimized slurry composition for tape casting, ${ }^{12}$ as they have a considerable influence on the green cast tapes by determining their quality, strength, and flexibility. ${ }^{22}$ The surface area determines the interaction of the ceramic with the organic additives, and the moderately small particle size helps in the uniform dispersion of the fillers in the slurry. Because CMO and CMOA show a similar particle size and density, the slurry composition (Table 1) used is same for both of them.

The chemical nature of the organic ingredients used in the tape casting slurry has an effect on the surrounding environment. Although water would be environmentally the ideal solvent, it has many disadvantages in tape casting because of its slow evaporation rate and agglomeration, etc. ${ }^{23}$ The 
Table 1. Slurry Composition for the Tape Casting

\begin{tabular}{llc}
\multicolumn{1}{c}{ ingredients } & \multicolumn{1}{c}{ materials } & content (wt \%) \\
ceramic powder & CMO/CMOA & 50 \\
binder & PPC-poly(propylene carbonate) & 3.6 \\
plasticizer-I & BBP-butyl benzyl phthalate & 1.2 \\
plasticizer-II & PEG-polyethylene glycol & 1.2 \\
solvent & DMC-dimethyl carbonate & 44 \\
\hline
\end{tabular}

problem was solved by using DMC, which is reported to be a highly reactive nontoxic solvent and a dispersant. ${ }^{14,15}$ PPC is known as an environmentally friendly binder, ${ }^{24-26}$ as it leaves a low residue after burnout and has a low burnout temperature. The green cast tapes of $\mathrm{CMO}$ and $\mathrm{CMOA}$ had single-layer thicknesses of 0.111 and $0.120 \mathrm{~mm}$, respectively. The mechanical strength of the green tapes is important for further processing. The single-layer tensile strengths of these CMO and CMOA tapes were 0.17 and $0.19 \mathrm{MPa}$, respectively, with a standard deviation of 0.02 . These values are comparable to some of the reported LTCC tapes ${ }^{27,28}$ but are of course lower than those of the commercial LTCCs because of their welloptimized slurry composition and harder binders that can be used at the higher sintering temperature.

Sintering and Cofiring. The TG/DSC analysis of the green cast tapes shown in Figure 2 gives an overall idea about

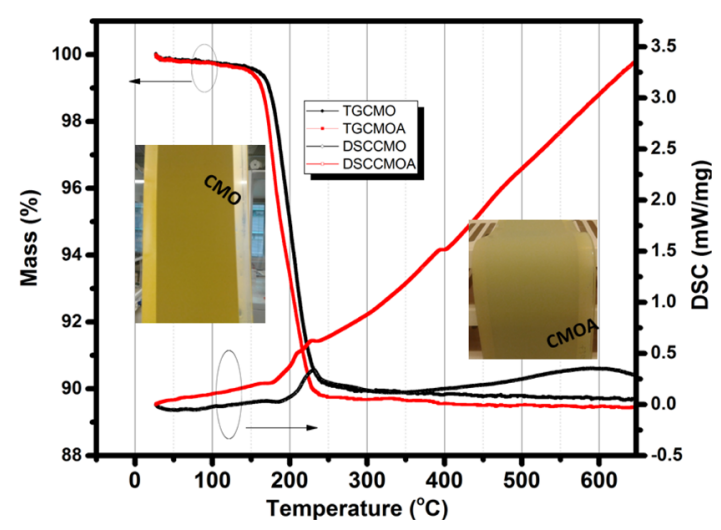

Figure 2. TG/DSC curve of CMO and CMOA green cast tapes (inset figure: photographic images of the green cast tapes).

the burnout temperature of the organic additives. It is necessary to annihilate the organic additives before sintering to prevent their effects on the shrinkage or electrical properties of the sintered substrates. A managed burnout also minimizes defects such as delamination, cracking, and anisotropic shrinkage during sintering. ${ }^{29}$ It was observed that the weight loss was slow for both the tapes up to $150{ }^{\circ} \mathrm{C}$ with a sharp increase to about $10 \%$ in the temperature range of $150-250$ ${ }^{\circ} \mathrm{C}$, corresponding to the removal of the binder and plasticizer. Also, exothermic peaks could be observed around $200-230^{\circ} \mathrm{C}$ in the DSC: these were due to the strong decomposition of the low-molecular-weight organics such as the binder and plasticizer. The TG and DSC curves of both green cast tapes were similar because the type and amount of organics used in the tapes were the same. However, the small peak at around $400{ }^{\circ} \mathrm{C}$ observed in the DSC of the CMOA tape was due to the formation of a new compound, $\mathrm{Cu}_{2} \mathrm{Ag}_{2}\left(\mathrm{MoO}_{4}\right)_{3}$, because of the reaction of $\mathrm{Ag}$ obtained by the decomposition of $\mathrm{Ag}_{2} \mathrm{O}$ with $\mathrm{CMO}$ and was expected to melt around $500{ }^{\circ} \mathrm{C}$, as we have reported earlier. ${ }^{17}$
TG analysis of the individual constituents, slurry without and slurry with the ceramic, was done to gain more detailed information on the thermal decompositions (Figure 3). It is

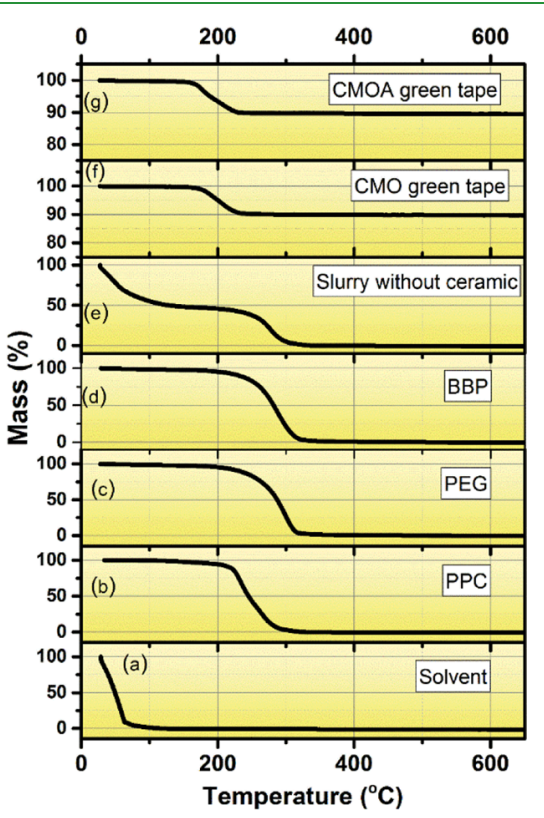

Figure 3. TG curve of ingredients used in the present tape casting composition $(\mathrm{a}-\mathrm{d})$, slurry without ceramic $(\mathrm{e})$, and green cast tapes [CMO (f) and CMOA (g)].

clear that the solvent was removed first below $100{ }^{\circ} \mathrm{C}$ (Figure $3 \mathrm{a})$. After that the binder removal started below $200{ }^{\circ} \mathrm{C}$ and ended at about $300{ }^{\circ} \mathrm{C}$ (Figure $3 \mathrm{~b}$ ), when the plasticizers were also removed (Figure $3 \mathrm{c}, \mathrm{d}$ ). The removal phase of the individual components from the slurry without the ceramics are clearly visible from Figure $3 \mathrm{e}$, where a weight loss of $50 \%$ occurred below $100{ }^{\circ} \mathrm{C}$ (solvent) and the rest was removed between 200 and $300{ }^{\circ} \mathrm{C}$ (because of the binder and plasticizers). Figure 3f,g gives information on the TG of the green cast tapes where a weight loss of about $10 \%$ occurred below $250{ }^{\circ} \mathrm{C}$. The presence of ceramic is evident as it corresponds to the decrease in the decomposition temperature as compared to the individual constituents shown in Figure 3. The green cast tapes used were dried, and hence, a low weight loss below $100{ }^{\circ} \mathrm{C}$ owing to the solvent was observed. It is also clear from Figure $3 \mathrm{a}-\mathrm{e}$ that the weight loss was almost $100 \%$, indicating a high level of burnout of the organics. However, it was difficult to achieve a complete residual-free tape after sintering because of the trapping of the organics, and the corresponding low residual carbon content is further confirmed by XPS.

On the basis of these results, the sintering profile of the substrates was carefully optimized by varying the sintering rates and dwell time to obtain a densified tape with a uniform microstructure affecting the performance of the final module. $^{22,30}$ Figure $S 1$ in the Supporting Information gives the effect of sintering rate and intermediate dwell time upon densification of the CMO substrate. A faster heating rate with a minimum intermediate dwell time increases the densification, which corresponds to the fast grain growth. Figure 4 shows the optimized sintering profile of the CMO and CMOA substrates. Both substrates had the same sintering profile with a difference only in their sintering temperature because the type and amount of organic additives used were the same. The removal 


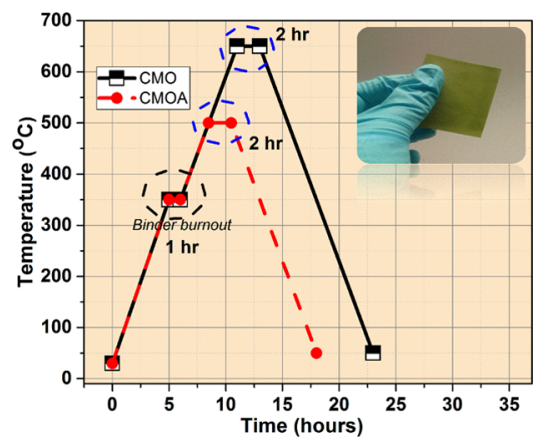

Figure 4. Sintering profile of $\mathrm{CMO}$ and $\mathrm{CMOA}$ substrates (inset figure: photographic image of the sintered substrate).

of the organic components was ensured by $1 \mathrm{~h}$ dwell time at $350{ }^{\circ} \mathrm{C}$. CMO was well sintered with $95 \%$ densification after sintering at $650{ }^{\circ} \mathrm{C}$ and about the same value was achieved in $\mathrm{CMOA}(96 \%)$ with a lower sintering temperature $\left(500{ }^{\circ} \mathrm{C}\right)$ because of the formation of a low melting compound. ${ }^{17}$ These densification values are almost the same as those reported earlier for the bulk samples. ${ }^{16,17}$ Five-layer stacks of sintered $\mathrm{CMO}$ and CMOA substrates were produced with thicknesses of 0.430 and $0.450 \mathrm{~mm}$, respectively. The sintered stacks shown in the inset of Figure 4 were hard and robust with a deep green color.

The sintered substrates had shrinkages of $15 \pm 1,14 \pm 1$, and $12 \pm 2 \%$, respectively, in the $X, Y$, and $Z$ directions for the CMO stacks and $16.5 \pm 1,16.0 \pm 1$, and $14 \pm 2 \%$, respectively, for CMOA, which are in the desired range for commercial production. ${ }^{31}$ Shrinkage is important for practical substrate applications as it restricts the substrate size that can be processed, which may create complexity in processing as well as in the embedded passive components. ${ }^{32}$

XPS surface analysis was performed on the green and sintered substrates (CMO and CMOA) to obtain more information on the residual carbon, and the results were compared with the commercial LTCC substrates $9 \mathrm{k} 7$ and 951. ${ }^{18,19}$ The survey spectra of the green and sintered 9k7, 951,
CMO, and CMOA substrates shown in Figure 5a,b provide an insight into the carbon content of these substrates. Highly intense $C 1 \mathrm{~s}$ peaks which are seen for the green substrates (Figure 5a) become barely visible in the spectra of the sintered samples (Figure $5 b$ ). High-resolution C 1 s spectra of the green and sintered substrates are given as Figure S2 in the Supporting Information. The decrease in the carbon content with sintering is more evident from Table 2, which presents the

Table 2. Atomic wt \% of Carbon in the Green and Sintered Commercial 9k7 and 951 and CMO and CMOA Substrates

\begin{tabular}{ccc} 
& \multicolumn{2}{c}{ carbon atomic wt $\% \pm 1.5 \%$} \\
\cline { 2 - 3 } sample name & green & sintered \\
CMO & 40.2 & 4.5 \\
CMOA & 44.4 & 4.3 \\
951 & 65.2 & 5.1 \\
$9 \mathrm{k} 7$ & 75.8 & 3.0 \\
\hline
\end{tabular}

atomic wt \%. It is clear that the carbon content was less than 5 wt $\%$ in both the substrates after sintering and can also be accounted within the error limit owing to the surface carbon atoms because of the surface roughness of the substrate compared with the XPS analysis depth. Hence, the results are in agreement with the TG analysis depicted in Figure 3. The results are well in line with the results for the commercial LTCC substrates.

Moreover, the carbon content in the ULTCC green laminates was lower and possibly corresponds to the composition as well as the molecular weight of the organics used to obtain a lower burnout temperature. This in turn can reduce the carbon burnout, which is an added advantage of these ULTCC compositions. These results indicate that the composition used in the present work provides much less carbon burnout as well as less residual carbon, which is both a necessity and a great advantage to the future electronics and communication industry.
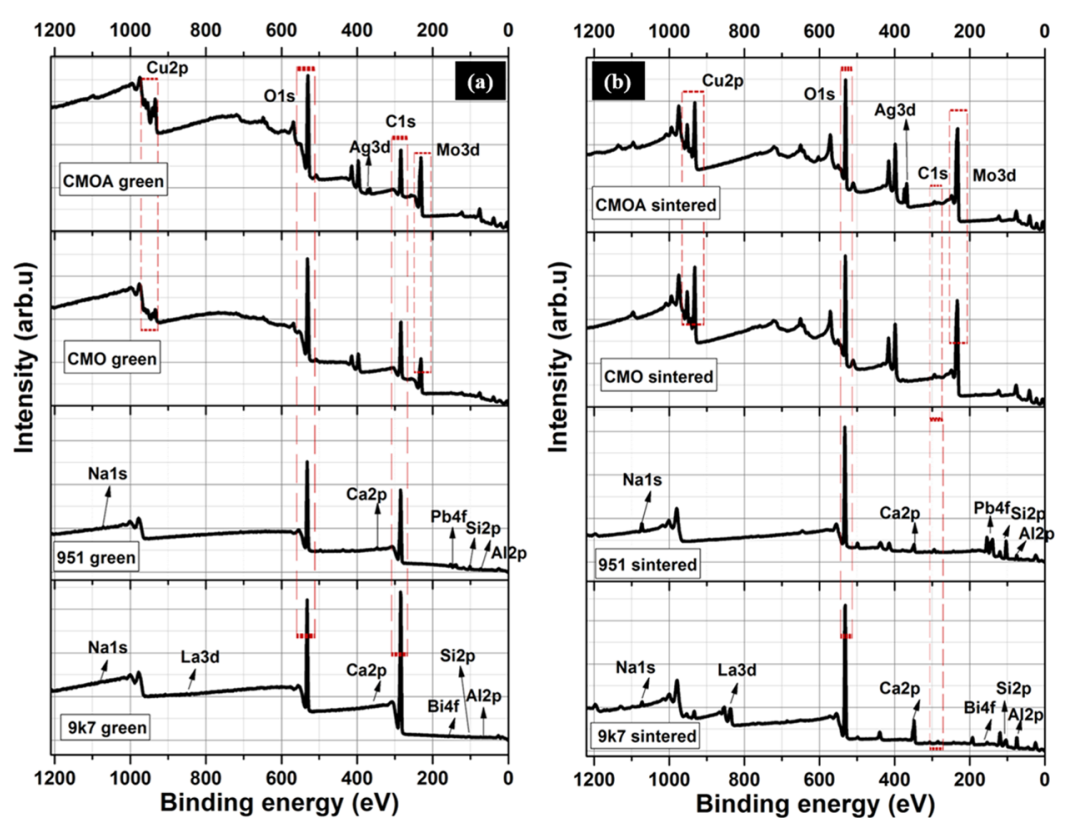

Figure 5. XPS survey spectra of (a) green and (b) sintered substrates (commercial 9k7 and 951 and CMO and CMOA substrates). 

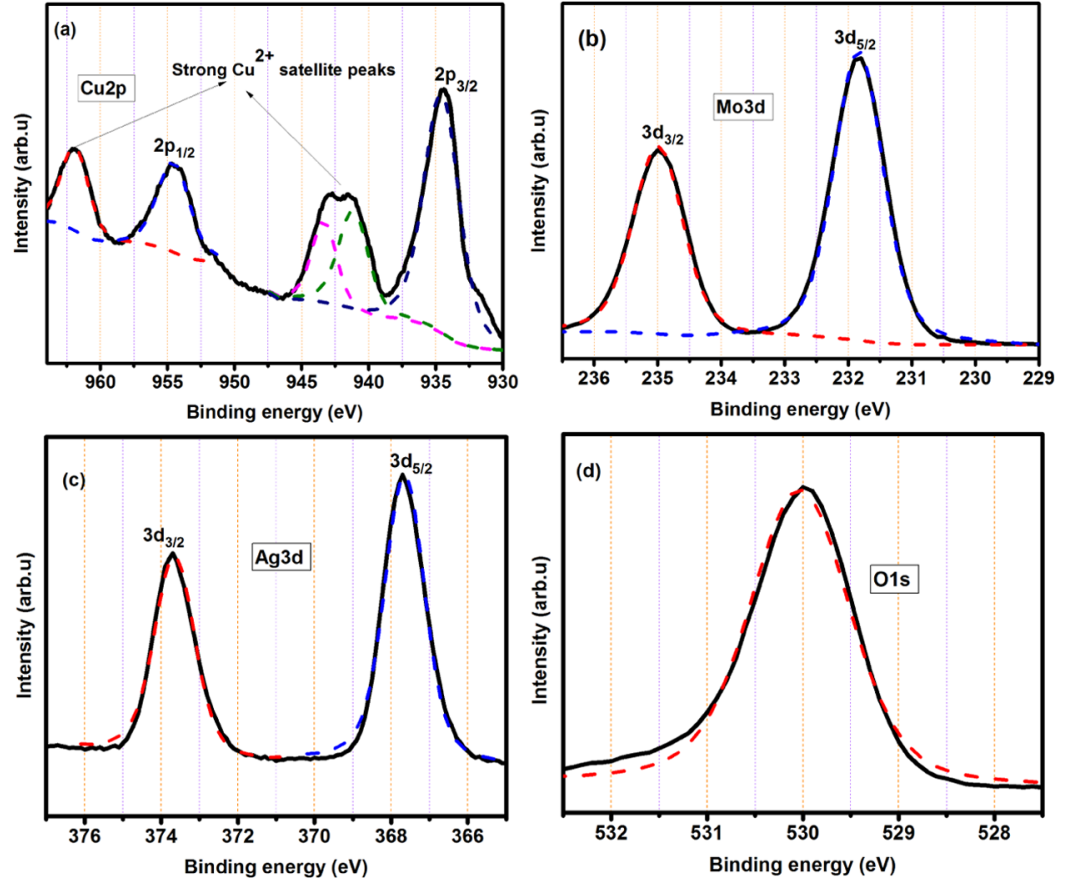

Figure 6. High-resolution spectra of (a) Cu 2p, (b) Mo 3d, (c) Ag 3d, and (d) O 1s of the sintered CMOA substrate.
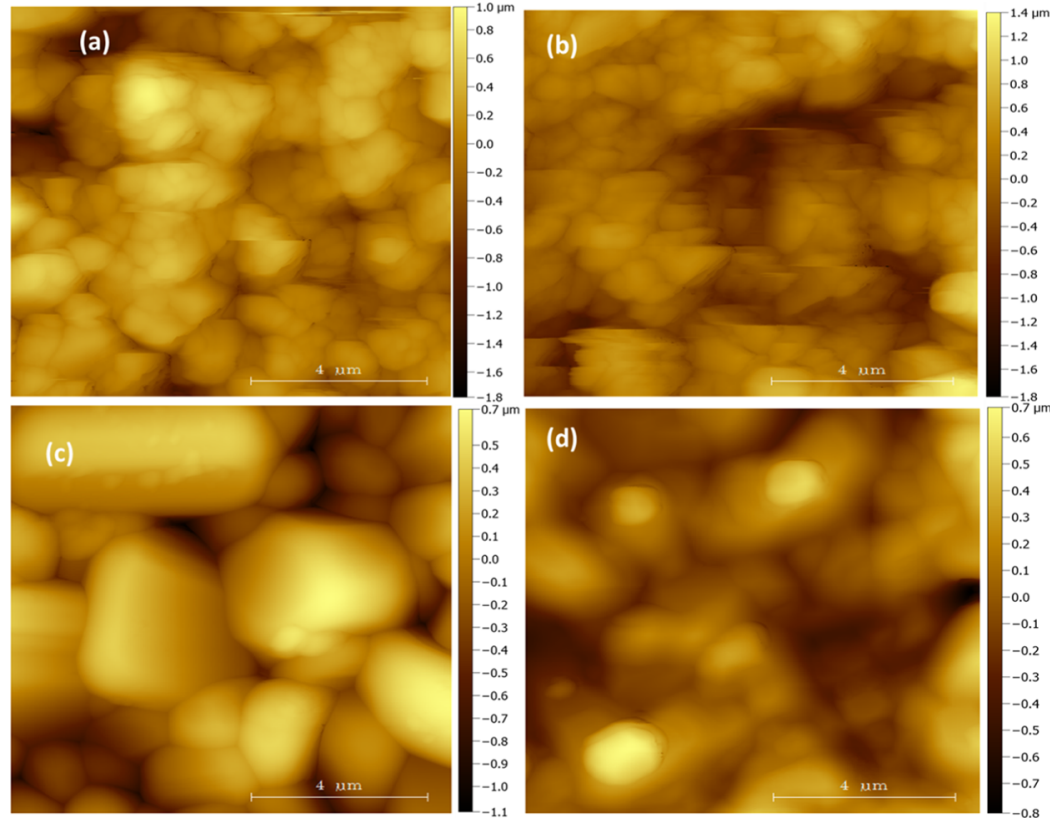

Figure 7. 2D AFM images of green (a) CMO and (b) CMOA and sintered (c) CMO and (d) CMOA substrates.

Figure 6 presents the high-resolution $\mathrm{Cu} 2 \mathrm{p}$, Mo 3d, Ag 3d, and $\mathrm{O} 1 \mathrm{~s}$ spectra and the curve level fitting observed for the sintered CMOA ceramic in which the $\mathrm{Cu} 2 \mathrm{p}, \mathrm{Mo} 3 \mathrm{~d}$, and $\mathrm{O} 1 \mathrm{~s}$ spectra are similar to those of CMO as it is the major phase. ${ }^{16}$ The high-resolution $\mathrm{Cu} 2 \mathrm{p}$ (Figure 6a) shows the spin-orbital splitting components of $2 \mathrm{p}_{3 / 2}$ and $2 \mathrm{p}_{1 / 2}$ by about $19.98 \mathrm{eV}$, while the full width at half-maximum (fwhm) values of the corresponding peaks are 3.11 and $2.86 \mathrm{eV}$, respectively. Strong satellite $\mathrm{Cu}^{2+}$ peaks are also observed, indicating the oxidation state of $\mathrm{Cu}$. The high-resolution spectrum of Mo 3d (Figure $6 \mathrm{~b}$ ) shows the spin-orbital splitting of $3 \mathrm{~d}_{5 / 2}$ and $3 \mathrm{~d}_{3 / 2}$ having an orbital split of about $3.15 \mathrm{eV}$ and fwhm of 0.92 and $0.93 \mathrm{eV}$, respectively. ${ }^{16,33}$ The high-resolution $\mathrm{Ag} 3 \mathrm{~d}$ spectrum (Figure
$6 c)$ exhibits the spin-orbital splitting of $3 \mathrm{~d}_{5 / 2}$ and $3 \mathrm{~d}_{3 / 2}$ by about $6 \mathrm{eV}$ with fwhm of 1.25 and $1.24 \mathrm{eV}$, respectively. This further confirms the presence of $\mathrm{Ag}$ in $\mathrm{CMO}$, which is difficult to be observed because of its low amount. The $\mathrm{O} 1 \mathrm{~s}$ photoelectron peak at about $530 \mathrm{eV}$ depicted in Figure $6 \mathrm{~d}$ gives information on the oxide ion in the sintered substrate with different chemical bondings and possibly corresponds to the bridging oxygen atoms, showing good agreement with reported values. $^{16,19,34}$ The fitted binding energies of $\mathrm{Cu} 2 \mathrm{p}$, Mo 3d, $\mathrm{Ag} 3 \mathrm{~d}$, and $\mathrm{O} 1 \mathrm{~s}$ are given in the Supporting Information (Table S1).

Surface Analysis and Microstructure. The surface quality of the tapes and sintered substrates is critical for 
microelectronic applications because it influences the accuracy of the printed electrodes and their performance through the skin depth at high frequencies. Two-dimensional (2D) atomic force microscopy (AFM) images of the green and sintered substrates shown in Figure 7 and the corresponding threedimensional (3D) images shown in the Supporting Information (Figure S3) indicate that the grains were distributed in the form of hills and valleys. It is also clear that the grains were larger after sintering, which indicates grain growth as well as the removal of organics. Analysis of the topography scans of the sample surfaces provides the roughness parameters, which includes average roughness $\left(R_{\mathrm{a}}\right)$, root-mean-square roughness (rms), skewness (skew), and kurtosis. The roughness parameters of the tapes are given in Table 3. The CMO and

Table 3. Surface Quality of the Green and Sintered Substrates

\begin{tabular}{cccccc} 
& \multicolumn{2}{c}{ green tape } & & \multicolumn{2}{c}{ sintered tape } \\
\cline { 2 - 3 } \cline { 5 - 6 } surface parameters & CMO & CMOA & & CMO & CMOA \\
$R_{\mathrm{a}}(\mathrm{nm})$ & 257 & 302 & & 157 & 172 \\
rms $(\mathrm{nm})$ & 329 & 380 & & 202 & 215 \\
skew & -0.6 & -0.1 & & 0.6 & 0.3 \\
kurtosis & 0.9 & 0.7 & & 0.4 & 0.1 \\
\hline
\end{tabular}

CMOA green tapes exhibited average surface roughnesses of $257 \pm 11$ and $302 \pm 10 \% \mathrm{~nm}$, respectively, which is reported to be comparable to commercial LTCC tapes. ${ }^{28,35}$ The skew value measures the asymmetry of the surfaces, and both the green tapes had negative skew values of -0.6 and -0.1 , which indicate that they had good bearing surfaces and were suitable for device fabrication. The negative value indicates that the surfaces had a longer tail distribution below the reference plane, that is, the valleys were predominant on the surface of the tapes, which is also evident from the $2 \mathrm{D}$ and $3 \mathrm{D}$ images. Kurtosis measures the distribution of the spikes above and below the mean line/plane. ${ }^{28,36}$ The green tapes had a kurtosis of $0.9-0.7$, meaning that the surface was flatter and is referred to as platykurtic. The kurtosis value indicates that the surface was not spiky but bumpy, which is in agreement with the images. $^{36,37}$ Similarly, for the sintered CMO and CMOA substrates, the average surface roughness decreased to $157 \pm 6$ and $172 \pm 5 \% \mathrm{~nm}$, respectively. The low average surface roughness may correspond to the uniformity of the surface obtained by sintering after the removal of all organic additives as well as to the increased densification. The positive skew values of 0.6 (CMO) and 0.3 (CMOA) indicate the brittle nature of the sintered tapes. Similar to the green substrates, the sintered substrates also had a bumpy surface rather than spikes as their kurtosis value was less than $3(0.4$ and 0.1$),{ }^{28,35-37}$ which is also evident from the images.

A more detailed microstructure of the green and sintered substrates was obtained from the SEM image shown in the Supporting Information and Figures S4 and 8. The microstructure of the green $\mathrm{CMO}$ and $\mathrm{CMOA}$ substrates with different magnifications shown in Figure S4 indicated that the green tape appeared to be dense with little porosity as the polymer binder binds the particles together during thermolamination. The morphology of the thermo-laminated stack revealed that the thermo-lamination conditions resulted in the merging of individual layers into a homogeneous coherent body during sintering. This may correspond to the good slurry composition. The microstructure of the sintered and cofired substrates with $\mathrm{Al}$ ink is presented in Figure 8. The sintered tape microstructure appeared to be dense and homogeneous with the removal of all organic additives. Substantial grain growth was observed and was tightly packed with good densification, which is clear from the backscattered secondary electron images shown in Figure 8a,b. Energy-dispersive X-ray spectrum (EDS) line map shown in Figure $8 \mathrm{c}, \mathrm{d}$ further confirmed that both substrates were free from all organics. The cofired CMO sintered substrate consisted solely of $\mathrm{Cu}, \mathrm{Mo}$, and $\mathrm{O}_{2}$, while the presence of a small amount of $\mathrm{Ag}$ was observed in the cofired CMOA substrate, as expected.

Aluminum powder does not react with the CMO ceramic as well as with $\mathrm{CMOA}$ on sintering at 650 and $500{ }^{\circ} \mathrm{C}$,
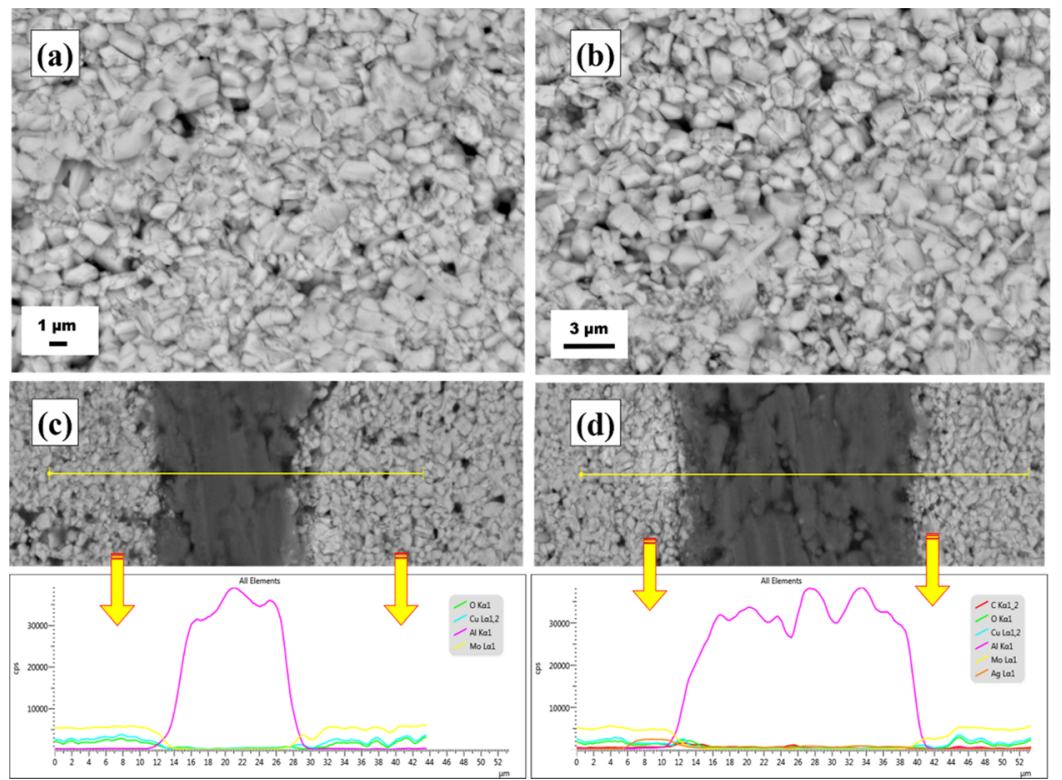

Figure 8. BSE images of sintered (a) CMO and (b) CMOA substrates, cofired, and (c) CMO and (d) CMOA substrates with EDS line mapping of the ceramic-metal interface. 
Table 4. Microwave Dielectric Properties of the Sintered Substrates

\begin{tabular}{|c|c|c|c|c|c|c|}
\hline \multirow[b]{3}{*}{ materials } & \multicolumn{6}{|c|}{ microwave dielectric properties } \\
\hline & \multicolumn{2}{|c|}{$2.4 \mathrm{GHz}$} & \multicolumn{2}{|c|}{$5.1 \mathrm{GHz}$} & \multicolumn{2}{|c|}{$9.9 \mathrm{GHz}$} \\
\hline & $\varepsilon_{\mathrm{r}} \pm 2 \%$ & $\tan \delta \pm(7-10 \%)$ & $\varepsilon_{\mathrm{r}} \pm 1 \%$ & $\tan \delta \pm(7-10 \%)$ & $\varepsilon_{\mathrm{r}} \pm 1 \%$ & $\tan \delta \pm(7-10 \%)$ \\
\hline CMO & 7.7 & $7.3 \times 10^{-5}$ & 7.6 & $1.8 \times 10^{-4}$ & 7.5 & $2.4 \times 10^{-4}$ \\
\hline CMOA & 7.8 & $3.5 \times 10^{-4}$ & 7.7 & $3.7 \times 10^{-4}$ & 7.7 & $4.2 \times 10^{-4}$ \\
\hline
\end{tabular}

respectively, as reported in our earlier studies. ${ }^{16,17}$ As evident from the backscattered electron (BSE) images and EDS line mapping of the ceramic-metal interface shown in Figure 8c,d, no reaction layer as well as no diffusion of the electrode into the ceramic was observed. These results indicate the chemical compatibility between the electrode and the ceramic in the multilayer ceramic substrate.

Microwave Dielectric Properties of Substrates. The dielectric properties of the substrate play a vital role in governing the signal transmission, that is, in determining the circuit speed because it acts as a support material for active and passive devices and for the interconnecting conductors that make up the substantial subsystems. The dielectric properties measured at gigahertz frequencies are of great interest because of the active development of mobile communications. ${ }^{38,39}$ The Supporting Information (Table S2) represents the microwave dielectric properties of green substrates (single-layer and fivelayer vacuum laminated) while those of five-layer vacuum laminated and sintered substrates of CMO and CMOA are given in Table 4. Both the green substrates exhibited low dielectric constant and high dielectric loss, which relates to the presence of organic additives.

The sintered substrates showed good microwave dielectric properties with $\varepsilon_{\mathrm{r}}$ in the range of approximately 8 . For both substrates, the $\varepsilon_{\mathrm{r}}$ was almost stable over the measured frequency ranges with a slightly decreasing tendency. The developed substrates exhibited a very low loss in the range of $10^{-5}$ to $10^{-4}$ over the measured frequency ranges. However, CMOA showed a slightly higher relative permittivity and dielectric loss compared to $\mathrm{CMO}$ owing to the presence of a small amount of the secondary phase. All these observations are well in line with the results achieved for the bulk samples. ${ }^{16,17}$ These dielectric properties indicate the potential of the developed substrate materials for microwave substrate applications at high frequencies. Figure 9 represents the variation of $\varepsilon_{\mathrm{r}}$ and $\tan \delta$ of the sintered CMO and CMOA substrates over the measured temperature range of -40 to 80 ${ }^{\circ} \mathrm{C}$ at $9.9 \mathrm{GHz}$. The relative permittivity increased with the temperature as expected. ${ }^{40}$ For both materials, $\varepsilon_{\mathrm{r}}$ increased almost linearly from 7.4 to $7.6(\mathrm{CMO})$ and from 7.6 to 7.7 (CMOA) without any abnormality with $\tau_{\varepsilon}$ values of 159 and $149 \mathrm{ppm} /{ }^{\circ} \mathrm{C}$, respectively. The thermal stability of these substrates could be further improved in the future by adding suitable additives. The $\tan \delta$ showed some variation with increasing temperature. However, both substrates exhibited a low dielectric loss in the range of $10^{-4}$ over the entire measured temperature range. The dielectric properties of these substrates were compared with a commercial LTCC DuPont $9 \mathrm{k} 7$ sintered at $850{ }^{\circ} \mathrm{C}$ and measured by the same SPDR measuring technique, which exhibited $\varepsilon_{\mathrm{r}}=7.4, \tan \delta=11 \times$ $10^{-4}$, and $\tau_{\varepsilon}=159 \mathrm{ppm} /{ }^{\circ} \mathrm{C}\left(-40\right.$ to $\left.80{ }^{\circ} \mathrm{C}\right)$ at $9.9 \mathrm{GHz}$. The substrates developed in the present work had comparable $\varepsilon_{\mathrm{r}}$ and $\tau_{\varepsilon}$ with lower values of dielectric loss and sintering temperature than the commercial substrates. This highlights the potential of these ULTCC substrates for future micro-

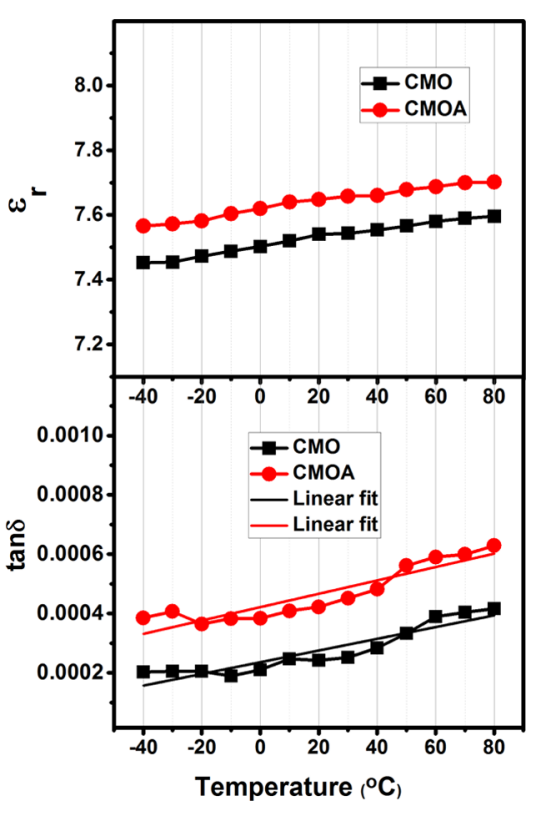

Figure 9. Temperature dependence of the dielectric properties of the sintered $\mathrm{CMO}$ and CMOA substrates.

electronic substrate applications as an environmentally friendly replacement for LTCC.

CTE of Substrates. The sintered CMO and CMOA substrates exhibited average low CTE values of 4.1 and 4.6 $\mathrm{ppm} /{ }^{\circ} \mathrm{C}$, respectively, in the temperature range of $25-300{ }^{\circ} \mathrm{C}$ being close to the CTE value of $\mathrm{Si}\left(4 \mathrm{ppm} /{ }^{\circ} \mathrm{C}\right)$, which enables the integration of these substrates with the semiconductor devices used in the electronics industry. This supports the prospect of these selected materials (CMO and CMOA) for device-level applications. ${ }^{41,42}$

To highlight the importance of the present work, a comparison in the properties of some commercial substrates (LTCC) and reported HTCC, LTCC, and ULTCC substrates is given in Table 5. It is clear from the table that the ULTCC substrates can achieve properties comparable to those of HTCC and LTCC substrates while having a very low sintering temperature. Moreover, a significant reduction in the sintering temperature of ULTCC systems in comparison with HTCC and LTCC fabrication temperatures further points to a future low-cost and sustainable fabrication technology. The considerable reduction in the fabrication temperature reduces the $\mathrm{CO}_{2}$ emission to some extent. ${ }^{50,51}$ Also, it should be noted that only very few ULTCCs have been used to realize substrates by tape casting as described in this work. The table emphasizes the significance of the present work in the growth of future substrate applications in the high-frequency ranges.

\section{CONCLUSIONS}

The ULTCC CMO and CMOA ceramic substrates were prepared by tape casting using environmentally friendly slurry 
Table 5. Comparison of the Properties of Some of the Commercial and Reported HTCC, LTCC, and ULTCC Substrates with Those of Our Present Work

\begin{tabular}{|c|c|c|c|c|c|c|}
\hline \multirow[b]{2}{*}{ commercial and research reports on microwave substrates } & \multirow[b]{2}{*}{ S.T. ${ }^{a}\left({ }^{\circ} \mathrm{C}\right)$} & \multirow[b]{2}{*}{$R_{\mathrm{a}}(\mathrm{nm})$} & \multicolumn{3}{|c|}{ microwave properties } & \multirow[b]{2}{*}{$\mathrm{CTE}\left(\mathrm{ppm} /{ }^{\circ} \mathrm{C}\right)$} \\
\hline & & & $\varepsilon_{\mathrm{r}}$ & $\tan \delta \times 10^{-4}$ & frequency & \\
\hline $\mathrm{Al}_{2} \mathrm{O}_{3}^{43}$ & 1700 & & $9.5-9.9$ & $1-4$ & $10 \mathrm{GHz}$ & $6-8$ \\
\hline $\mathrm{AlN}^{43}$ & 1900 & & $8.0-9.2$ & 10 & $1 \mathrm{MHz}$ & $4.2-5.8$ \\
\hline $\mathrm{ZrSiO}_{4}^{43}$ & 1600 & & 9.2 & 3 & $5 \mathrm{GHz}$ & -2.5 \\
\hline $\mathrm{ZAT}^{b^{4} 29}$ & 1150 & 85 & 9.6 & 8.4 & $5 \mathrm{GHz}$ & 6.59 \\
\hline $\mathrm{Sr}_{2} \mathrm{ZnTeO}_{6}(\mathrm{SZT})-5$ wt $\%$ of $\mathrm{ZBPT}^{c 37}$ & 900 & 154 & 12 & 20 & $5 \mathrm{GHz}$ & \\
\hline $\mathrm{Bi}_{4}\left(\mathrm{SiO}_{4}\right)_{3}^{28}$ & 900 & 320 & 13.3 & 7 & $15 \mathrm{GHz}$ & 7.09 \\
\hline $\mathrm{LiMgPO}_{4}^{27}$ & 900 & 250 & 6.4 & 2 & $5 \mathrm{GHz}$ & 10.5 \\
\hline indialite/cordierite glass- 10 wt $\% \mathrm{Bi}_{2} \mathrm{O}_{3}{ }^{44}$ & 900 & & 6.1 & 1 & $1 \mathrm{MHz}$ & 3.5 \\
\hline \multirow[t]{2}{*}{$\mathrm{SrCuSi}_{4} \mathrm{O}_{10}+5$ wt $\% \mathrm{LMZBS}^{d} 45$} & 900 & 560 & 4.8 & 16 & $5 \mathrm{GHz}$ & \\
\hline & & & 4.7 & 19 & $15 \mathrm{GHz}$ & \\
\hline \multirow[t]{3}{*}{$\mathrm{Li}_{2} \mathrm{ZnTi}_{3} \mathrm{O}_{8}(\mathrm{LZT})-1$ wt $\% \mathrm{LMZBS}^{d} 46$} & 875 & 151 & 21.9 & 2 & $5 \mathrm{GHz}$ & 11.97 \\
\hline & & & 21.5 & 4 & $10 \mathrm{GHz}$ & \\
\hline & & & 21.3 & 7 & $15 \mathrm{GHz}$ & \\
\hline $\mathrm{Sr}_{2} \mathrm{ZnSi}_{2} \mathrm{O}_{7}+15$ wt $\%$ LMZBS $^{d} 47$ & 875 & & 6.9 & 15 & $20 \mathrm{GHz}$ & \\
\hline DuPont $9 \mathrm{k} 7^{\text {present work }}$ & 850 & & 7.4 & 11 & $9.9 \mathrm{GHz}$ & \\
\hline Ferro $\mathrm{A} 6^{43}$ & 850 & & 5.9 & 20 & $3 \mathrm{GHz}$ & 7 \\
\hline $40 \mathrm{Al}_{2} \mathrm{O}_{3}-60 \mathrm{BBSZ}^{e} 48$ & 850 & 299 & 10.9 & 90 & $5 \mathrm{GHz}$ & 6.9 \\
\hline $40 \mathrm{Al}_{2} \mathrm{O}_{3}-60 \mathrm{LABS}^{f} 49$ & 775 & 293 & 4.7 & 50 & $5 \mathrm{GHz}$ & 5.1 \\
\hline $\mathrm{LiWO}_{4}{ }^{10}$ & 650 & 182 & 5.4 & 0.92 & $5 \mathrm{GHz}$ & 16 \\
\hline silicon dioxide-filled zinc borate glass ${ }^{9}$ & 650 & & 6.4 & 10 & $1 \mathrm{MHz}$ & \\
\hline $\mathrm{Zn}_{2} \mathrm{Te}_{3} \mathrm{O}_{8}-$ titanium dioxide ${ }^{11}$ & 650 & & 17.3 & 60 & $7 \mathrm{GHZ}$ & \\
\hline \multirow[t]{3}{*}{$\mathrm{CMO}^{\text {present work }}$} & 650 & 257 & 7.67 & 0.73 & $2.4 \mathrm{GHz}$ & 4.1 \\
\hline & & & 7.60 & 1.8 & $5.1 \mathrm{GHz}$ & \\
\hline & & & 7.54 & 2.42 & $9.9 \mathrm{GHz}$ & \\
\hline \multirow[t]{3}{*}{$\mathrm{CMOA}^{\text {present work }}$} & 500 & 302 & 7.80 & 3.50 & $2.4 \mathrm{GHz}$ & 4.7 \\
\hline & & & 7.71 & 3.70 & $5.1 \mathrm{GHz}$ & \\
\hline & & & 7.68 & 4.22 & $9.9 \mathrm{GHz}$ & \\
\hline
\end{tabular}

${ }^{a}$ S.T.-sintering temperature. ${ }^{b} \mathrm{ZAT}-0.83 \mathrm{ZnAl}_{2} \mathrm{O}_{4}-0.17 \mathrm{TiO}_{2}$ (in moles). ${ }^{c} \mathrm{ZBPT}-10 \mathrm{~mol} \% \mathrm{ZnO}-2 \mathrm{~mol} \% \mathrm{~B}_{2} \mathrm{O}_{3}-8 \mathrm{~mol} \% \mathrm{P}_{2} \mathrm{O}_{5}-80 \mathrm{~mol} \%$ $\left.\mathrm{TeO}_{2} .{ }^{d} \mathrm{LMZBS}-20 \mathrm{Li}_{2} \mathrm{O} / 20 \mathrm{MgO} / 20 \mathrm{ZnO} / 20 \mathrm{~B}_{2} \mathrm{O}_{3} / 20 \mathrm{SiO}_{2} .{ }^{e} \mathrm{BBSZ}_{-}-35 \mathrm{Bi}_{2} \mathrm{O}_{3} / 32 \mathrm{ZnO} / 27 \mathrm{~B}_{2} \mathrm{O}_{3} / 6 \mathrm{SiO}_{2}\right) .{ }_{\mathrm{LABS}}-40 \mathrm{Li}_{2} \mathrm{CO}_{3} / 10 \mathrm{Al}_{2} \mathrm{O}_{3} / 30 \mathrm{~B}_{2} \mathrm{O}_{3} /$ $20 \mathrm{SiO}_{2}$.

compositions, followed by sintering at 650 and $500{ }^{\circ} \mathrm{C}$, respectively. The results showed that the developed slurry composition was feasible for these ULTCCs with completed burnout below $300{ }^{\circ} \mathrm{C}$, leaving very low residual carbon (less than 5\%). This was at the same level as measured for the commercial LTCCs. The densification of both ceramics ( $\geq 95 \%$ ) was close to that measured for the bulk samples, as were the dielectric properties $\left(\varepsilon_{\mathrm{r}}=8, \tan \delta=10^{-5}\right.$ to $10^{-4}$ at $2-10 \mathrm{GHz})$. Moreover, the substrates had a low CTE of around $4-5 \mathrm{ppm} /{ }^{\circ} \mathrm{C}$, close to that of the $\mathrm{Si}$ semiconductor, and could be cofired with embedded $\mathrm{Al}$ electrodes. Hence, the results show that the developed substrates fabricated by an environmentally friendly approach fulfill the demands of low residual carbon and also enable the fabrication of multilayer substrates with good mechanical, thermal, and dielectric properties.

\section{ASSOCIATED CONTENT}

\section{S Supporting Information}

The Supporting Information is available free of charge on the ACS Publications website at DOI: 10.1021/acsami.9b07272.

Sintering profile optimization of the CMO substrate; high-resolution $\mathrm{C} 1 \mathrm{~s}$ spectrum of green and sintered substrates (9k7, 951, CMO, and CMOA); 3D AFM images of green and sintered $\mathrm{CMO}$ and $\mathrm{CMOA}$ substrates; microstructure of green laminated $\mathrm{CMO}$ and CMOA substrates at different magnifications; binding energy of $\mathrm{Cu} 2 \mathrm{p}$, Mo 3d, $\mathrm{Ag} 3 \mathrm{~d}$, and $\mathrm{O} 1 \mathrm{~s}$ in electronvolts; and microwave dielectric properties of the green tapes (PDF)

\section{AUTHOR INFORMATION}

\section{Corresponding Author}

*E-mail: ninajoseph11@gmail.com.

\section{ORCID}

Nina Joseph: 0000-0002-4970-4442

Jobin Varghese: 0000-0003-3985-9181

\section{Notes}

The authors declare no competing financial interest.

\section{ACKNOWLEDGMENTS}

The authors are thankful to European Research Council (ERC) project no. 24001893 and ERC POC no. 812837 for the financial support. The second author is grateful to the Ulla Tuominen Foundation project grant in 2018. This work was also partially supported by the Academy of Finland 6Genesis Flagship (grant 318927).

\section{REFERENCES}

(1) Sebastian, M. T.; Wang, H.; Jantunen, H. Low Temperature Cofired Ceramics with Ultralow Sintering Temperature: A Review. Curr. Opin. Solid State Mater. Sci. 2016, 20, 151-170. 
(2) Roosen, A. Ceramic Substrates: Trends in Materials and Applications. Ceram. Trans. 2000, 106, 479-492.

(3) Stiegelschmitt, A.; Roosen, A.; Ziegler, C.; Martius, S.; Schmidt, L.-P. Dielectric Data of Ceramic Substrates at High Frequencies. J. Eur. Ceram. Soc. 2004, 24, 1463-1466.

(4) Zhang, G.-q.; Guo, J.; Wang, H. Ultra Low Temperature Sintering Microwave Dielectric Ceramics Based $\mathrm{Ag}_{2} \mathrm{O}-\mathrm{MoO}_{3}$ Binary System. J. Am. Ceram. Soc. 2017, 100, 2604-2611.

(5) Varghese, J.; Siponkoski, T.; Nelo, M.; Sebastian, M. T.; Jantunen, H. Microwave Dielectric Properties of Low-Temperature Sinterable $\alpha-\mathrm{MoO}_{3}$. J. Eur. Ceram. Soc. 2018, 38, 1541-1547.

(6) Varghese, J.; Siponkoski, T.; Teirikangas, M.; Sebastian, M. T.; Uusimäki, A.; Jantunen, H. Structural, Dielectric, and Thermal Properties of $\mathrm{Pb}$ Free Molybdate Based Ultralow Temperature Glass. ACS Sustainable Chem. Eng. 2016, 4, 3897-3904.

(7) Varghese, J.; Gopinath, S.; Sebastian, M. T. Effect of Glass Fillers in $\mathrm{Cu}_{2} \mathrm{ZnNb}_{2} \mathrm{O}_{8}$ Ceramics for Advanced Microwave Applications. Mater. Chem. Phys. 2013, 137, 811-815.

(8) Neelakantan, U. A.; Kalathil, S. E.; Ratheesh, R. Structure and Microwave Dielectric Properties of Ulta low Temperature Cofirable $\mathrm{BaV}_{2} \mathrm{O}_{6}$ Ceramics. Eur. J. Inorg. Chem. 2015, 305-310.

(9) Yu, H.; Ju, K.; Liu, J.; Li, Y. Tape Casting and Dielectric Properties of $\mathrm{SiO}_{2}$-Filled Glass Composite Ceramic with an UltraLow Sintering Temperature. J. Mater. Sci.: Mater. Electron. 2014, 25, 5114-5118.

(10) Sasidharanpillai, A.; Kim, C. H.; Lee, C. H.; Sebastian, M. T.; Kim, H. T. Environmental Friendly Approach for the Development of Ultra-Low Firing $\mathrm{Li}_{2} \mathrm{WO}_{4}$ Ceramic Tapes. ACS Sustainable Chem. Eng. 2018, 6, 6849-6855.

(11) Honkamo, J.; Jantunen, H.; Subodh, G.; Sebastian, M. T.; Mohanan, P. Tape Casting and Dielectric Properties of $\mathrm{Zn}_{2} \mathrm{Te}_{3} \mathrm{O}_{8}$ Based Ceramics with an Ultra-Low Sintering Temperature. Int. J. Appl. Ceram. Technol. 2009, 6, 531-536.

(12) Varghese, J.; Siponkoski, T.; Sobocinski, M.; Vahera, T.; Jantunen, H. Multilayer Functional Tapes Cofired at $450{ }^{\circ} \mathrm{C}$ : Beyond HTCC and LTCC technologies. ACS Appl. Mater. Interfaces 2018, 10, 11048-11055

(13) Chen, M.-Y.; Vahera, T.; Hsi, C.-S.; Sobocinski, M.; Teirikangas, M.; Peräntie, J.; Juuti, J.; Jantunen, H. Tape Casting System for ULTCCs to Fabricate Multilayer and Multimaterial 3D Electronic Packages with Embedded Electrodes. J. Am. Ceram. Soc. 2017, 100, 1257-1260.

(14) Pyo, S.-H.; Park, J. H.; Chang, T.-S.; Hatti-Kaul, R. Dimethyl Carbonate as a Green Chemical. Curr. Opin. Green Sustain. Chem. 2017, 5, 61-66.

(15) Fiorani, G.; Perosa, A.; Selva, M. Dimethyl Carbonate: A Versatile Reagent for a Sustainable Valorization of Renewables. Green Chem. 2018, 20, 288-322.

(16) Joseph, N.; Varghese, J.; Siponkoski, T.; Teirikangas, M.; Sebastian, M. T.; Jantunen, H. Glass Free $\mathrm{CuMoO}_{4}$ Ceramic with Excellent Dielectric Properties for Ultra-Low Temperature Cofired Ceramic Applications. ACS Sustainable Chem. Eng. 2016, 4, 56325639.

(17) Joseph, N.; Varghese, J.; Teirikangas, M.; Sebastian, M. T.; Jantunen, H. Ultra-Low Sintering Temperature Ceramic Composites of $\mathrm{CuMoO}_{4}$ Through $\mathrm{Ag}_{2} \mathrm{O}$ Addition for Microwave Applications. Composites, Part B 2018, 141, 214-220.

(18) Muñoz-Márquez, M. A.; Maider, Z.; Elizabeth, C. M.; Aitor, E. B.; Teófilo, R.; Montse, C. C. Composition and Evolution of the Solid-Electrolyte Interphase in $\mathrm{Na}_{2} \mathrm{Ti}_{3} \mathrm{O}_{7}$ Electrodes for Na-ion Batteries: XPS and Auger Parameter Analysis. ACS Appl. Mater. Interfaces 2015, 7, 7801-7808.

(19) http://srdata.nist.gov/xps/main_search_menu.aspx (accessed 2018), accessed March 2019.

(20) Janezic, M. D.; Krupka, J. Split-post and split-cylinder resonator techniques: A Comparison of Complex Permittivity Measurement of Dielectric Substrates. J. Microelectron. Electron. Packag. 2009, 6, 97100.
(21) Krupka, J.; Gregory, A. P.; Rochard, O. C.; Clarke, R. N.; Riddle, B.; Baker-Jarvis, J. Uncertainty of Complex Permittivity Measurements by Split-Post Dielectric Resonator Technique. J. Eur. Ceram. Soc. 2001, 21, 2673-2676.

(22) Imanaka, Y. Multilayered Low Temperature Cofired Ceramics Technology; Springer: USA, 2005.

(23) Li, S.; Zhang, Q.; Yang, H.; Zou, D. Fabrication and Characterization of $\mathrm{Li}_{1+\mathrm{x}-\mathrm{y}} \mathrm{Nb}_{1-\mathrm{x}-3 \mathrm{y}} \mathrm{Ti}_{\mathrm{x}+4 \mathrm{y}} \mathrm{O}_{3}$ Substrates Using Aqueous Tape Casting Process. Ceram. Int. 2009, 35, 421-426.

(24) Ferraro, P.; Hanggodo, S.; Burn, I.; Baker, A.; Qu, W. Use of Polyalkylene Carbonate Binders for Improved Performance in Multilayer Ceramic Capacitors. Int. Symp. Microelectron. 2011, 2011, 000785-000788.

(25) Kramer, D. P.; Santangelo, J. G.; Weber, J. J. $\mathrm{CO}_{2}$ Copolymer Binder for Forming Ceramic Bodies and a Shaping Process Using the Same. U.S. Patent 4,882,110 A, Nov 21, 1987.

(26) Kramer, D. P.; Santangelo, J. G.; Weber, J. J. $\mathrm{CO}_{2}$ Copolymer Ceramic-Binder Composition. U.S. Patent 4,814,370 A, Jan 15, 1988.

(27) Thomas, D.; Abhilash, P.; Sebastian, M. T. Casting and Characterization of $\mathrm{LiMgPO}_{4}$ Glass free LTCC Tape for Microwave Applications. J. Eur. Ceram. Soc. 2013, 33, 87-93.

(28) Abhilash, P.; Sebastian, M. T.; Surendran, K. P. Glass Free, Non-Aqueous LTCC Tapes of $\mathrm{Bi}_{4}\left(\mathrm{SiO}_{4}\right)_{3}$ with High Solid Loading. J. Eur. Ceram. Soc. 2015, 35, 2313-2320.

(29) Roshni, S. B.; Sebastian, M. T.; Surendran, K. P. Can Zinc Aluminate-Titania Composite be an Alternative for Alumina as Microelectronic Substrate? Sci. Rep. 2017, 7, 40839.

(30) Kingery, W. D.; Bowen, H. K.; Uhlman, D. R. Introduction to Ceramics, 2nd ed.; John Wiley and Sons: New York, 1976.

(31) Rosidah, A. Sintering of Ceramics-New Emerging Techniques; InTech: Croatia, 2012; ISBN:978-953-51-0017-1.

(32) Sebastian, M. T.; Ubic, R.; Jantunen, H. Microwave Materials and Applications; Wiley, 2017.

(33) Biesinger, M. C.; Lau, L. W. M.; Gerson, A. R.; Smart, R. S. C. Resolving Surface Chemical States in XPS Analysis of first Row Transition Metals Oxides and Hydroxides:Sc, Ti, V, Cu and Zn. Appl. Surf. Sci. 2010, 257, 887-898.

(34) Chigrin, P. G.; Lebukhova, N. V.; Ustinov, A. Y. Structural Transformation of $\mathrm{CuMoO}_{4}$ in the Catalytic Oxidation of Carbon. Kinet. Catal. 2013, 54, 76-80.

(35) Raoufi, D.; Kiasatpour, A.; Fallah, H. R.; Rozatian, A. S. H. Surface Characterization and Microstructure of ITO Thin Films at Different Annealing Temperatures. Appl. Surf. Sci. 2007, 253, 90859090.

(36) Kumar, B. R.; Rao, T. S. AFM Studies on Surface Morphology, Topography and Texture of Nanostructured Zinc Aluminum Oxide Thin Films. Dig. J. Nanomater. Biostruct. 2012, 7, 1881-1889.

(37) Abhilash, P.; Roshni, S. B.; Mohanan, P.; Surendran, K. P. A Facile Development of Homemade Substrate Using 'Quench Free' Glass-Ceramic Composite and Printing Microstrip Patch Antenna on it. Mater. Des. 2018, 137, 38-46.

(38) Alford, N. M.; Penn, S. J. Sintered Alumina with Low Dielectric Loss. J. Appl. Phys. 1996, 80, 5895-5898.

(39) Rosidah, A. Structural and Dielectric Properties of Glass-Ceramic Substrate with Varied Sintering Temperatures, Sintering Applications Burcu; E. Intech Open: Croatia, 2013.

(40) Sebastian, M. T. Dielectrics for Wireless Communications; Elsevier: U.K., 2008

(41) Varghese, J.; Présumey, M.; Sebastian, M. T.; Surendran, K. P. Structural, Dielectric and Thermal Properties of $\mathrm{Ca}_{9} \mathrm{R}_{2} \mathrm{~W}_{4} \mathrm{O}_{24}[\mathrm{R}-\mathrm{Nd}$, Sm] Ceramics. Mater. Chem. Phys. 2014, 148, 96-102.

(42) Varghese, J.; Joseph, T.; Surendran, K. P.; Rajan, T. P. D.; Sebastian, M. T. Hafnium Silicate: A New Microwave Dielectric Ceramic with Low Thermal Expansivity. Dalton Trans. 2015, 44, $5146-5152$

(43) Varghese, J.; Joseph, T.; Sebastian, M. T. $\mathrm{ZrSiO}_{4}$ Ceramics for Microwave Integrated Circuit Applications. Mater. Lett. 2011, 65, 1092-1094. 
(44) Varghese, J.; Vahera, T.; Ohsato, H.; Iwata, M.; Jantunen, H. Novel Low-Temperature Sintering Ceramic Substrate Based on Indialite/Cordierite Glass Ceramics. Jpn. J. Appl. Phys. 2017, 56, $10 \mathrm{PE} 01$.

(45) Manu, K.; Sebastian, M. T. Tape Casting of Low Permittivity Wesselsite-Glass Composite for LTCC Based Microwave Applications. Ceram. Int. 2016, 42, 1210-1216.

(46) Arun, S.; Sebastian, M. T.; Surendran, K. P. $\mathrm{Li}_{2} \mathrm{ZnTi}_{3} \mathrm{O}_{8}$ based high $\kappa$ LTCC Tapes for Improved Thermal Management in Hybrid Circuit Applications. Ceram. Int. 2017, 43, 5509-5516.

(47) Joseph, T.; Sebastian, M. T.; Jantunen, H.; Jacob, M.; Sreemoolanadhan, H. Tape Casting and Dielectric Properties of $\mathrm{Sr}_{2} \mathrm{ZnSi}_{2} \mathrm{O}_{7}$-Based Ceramic-Glass Composite for Low-Temperature Co-fired Ceramics Applications. Int. J. Appl. Ceram. Technol. 2011, 8, 854-864.

(48) Induja, I. J.; Abhilash, P.; Arun, S.; Surendran, K. P.; Sebastian, M. T. LTCC Tapes Based on $\mathrm{Al}_{2} \mathrm{O}_{3}$-BBSZ Glass with Improved Thermal Conductivity. Ceram. Int. 2015, 41, 13572-13581.

(49) Induja, I. J.; Varma, M. R.; Sebastian, M. T. Preparation, Characterization and Properties of Alumina-Lithium Aluminium Borosilicate Glass Based LTCC Tapes. J. Mater. Sci.: Mater. Electron. 2017, 28, 14655-14663.

(50) Heidary, D. S. B.; Lanagan, M.; Randall, C. A. Contrasting Energy Efficiency in Various Ceramic Sintering Processes. J. Eur. Ceram. Soc. 2018, 38, 1018-1029.

(51) Varghese, J.; Ramachandran, P.; Sobocinski, M.; Vahera, T.; Jantunen, H. ULTCC Glass Composites Based on Rutile and Anatase with Cofiring at $400{ }^{\circ} \mathrm{C}$ for High Frequency Applications. ACS Sustainable Chem. Eng. 2019, 7, 4274-4283. 